\title{
Testing the stress gradient hypothesis in herbivore communities: facilitation peaks at intermediate nutrient levels
}

\author{
Elisabeth S. Bakker, ${ }^{1,4}$ Ioana Dobrescu, ${ }^{1,2}$ Dietmar Straile, ${ }^{3}$ and Milena Holmgren ${ }^{2}$ \\ ${ }^{1}$ Department of Aquatic Ecology, Netherlands Institute of Ecology (NIOO-KNAW), Droevendaalsesteeg 10, \\ 6708 PB Wageningen, The Netherlands \\ ${ }^{2}$ Resource Ecology Group, Wageningen University, P.O. Box 47, 6700 AA, Wageningen, The Netherlands \\ ${ }^{3}$ Limnological Institute, University of Konstanz, Mainaustraße 252, 78464 Konstanz, Germany
}

\begin{abstract}
The role of positive interactions in structuring plant and animal communities is increasingly recognized, but the generality of current theoretical models has remained practically unexplored in animal communities. The stress gradient hypothesis predicts a linear increase in the intensity of facilitation as environmental conditions become increasingly stressful, whereas other theoretical models predict a maximum at intermediate environmental stress. We tested how competition and facilitation between herbivores change over a manipulated gradient of nutrient availability. We studied the effect of grazing by pond snails (Lymnaea stagnalis L.) as bulk grazers on aquatic caterpillars (Acentria ephemerella Denis and Schiffermüller) as small specialist grazers along an experimental gradient of environmental nutrient concentration. Higher nutrient levels increased overall total plant biomass but induced a shift toward dominance of filamentous algae at the expense of macrophytes. Facilitation of caterpillars by snail presence peaked at intermediate nutrient levels. Both caterpillar biomass and caterpillar grazing on macrophytes were highest at intermediate nutrient levels. Snails facilitated caterpillars possibly by removing filamentous algae and increasing access to the macrophyte resource, whereas they did not affect macrophyte biomass or $\mathrm{C}$ : nutrient ratios, a measure of food quality. We conclude that competition and facilitation in herbivore communities change along nutrient availability gradients that affect plant biomass and community composition. Understanding how interspecific interactions may change in strength and direction along environmental gradients is important to predict how the diversity and structure of communities may respond to the introduction or removal of herbivore species in ecosystems.
\end{abstract}

Key words: competition; food quality; food quantity; grazing; interspecific interaction; macrophyte; plant production; positive interaction; productivity gradient; stress gradient hypothesis.

\section{INTRODUCTION}

Positive interactions are increasingly recognized as important mechanisms structuring plant and animal communities in terrestrial, freshwater, and marine ecosystems (Bruno et al. 2003) by affecting both species diversity (Hacker and Gaines 1997) and ecosystem functioning (Cardinale et al. 2002, Duffy et al. 2003; but see Maestre et al. 2010). Current theoretical models on the role of facilitation along productivity and predator pressure gradients, predict either a linear increase in the intensity of facilitation as environmental conditions become increasingly stressful, the stress gradient hypothesis (Bertness and Callaway 1994, Le Bagousse-Pinguet et al. 2012b), or a maximum at intermediate environmental stress (Michalet et al. 2006, Maestre et al. 2009, Holmgren and Scheffer 2010). Empirical tests in plant communities support

Manuscript received 10 July 2012; revised 4 February 2013; accepted 8 February 2013; final version received 4 March 2013. Corresponding Editor: J. C. Trexler.

${ }^{4}$ E-mail: 1.bakker@nioo.knaw.nl both the linear model (Callaway et al. 2002, Cavieres et al. 2006) and the humped-shaped model along abiotic stress gradients (Maestre and Cortina 2004) and grazing pressure gradients (Brooker et al. 2006, Smit et al. 2007, Le Bagousse-Pinguet et al. 2012a). Meta-analysis attempting to summarize the empirical evidence in plant communities indicate either weak evidence for the linear stress gradient hypothesis (Maestre et al. 2005) or show nonlinear patterns suggesting that positive effects peak at intermediate conditions (Holmgren et al. 2012). The presence of multiple stress gradients and how large they are, may affect the shape of these relationships (Kawai and Tokeshi 2007, Smit et al. 2010, Bulleri et al. 2011).

Whereas positive interactions have also been documented in herbivore communities (Arsenault and OwenSmith 2002, Bakker et al. 2009), the relative role of facilitation and competition along environmental gradients remains poorly understood. Correlational and observational studies in mostly vertebrate herbivore communities, indicate that herbivores generally compete for plant resources at low productivity sites or years, corresponding with low rainfall or plant nutrient 
availability (Cheng and Ritchie 2006, Odadi et al. 2011), whereas there is some evidence that they may interact positively under highly productive conditions (Krueger 1986, Kuijper et al. 2008, Odadi et al. 2011). The generality of the theoretical models on the interplay of facilitation and competition along environmental gradients remains practically unexplored in herbivore communities. The best known cases on positive interactions between herbivores have been described in grasslands, where large herbivores indirectly facilitate smaller ones by increasing access to edible plants and by improving plant quality (Huisman and Olff 1998, Arsenault and Owen-Smith 2002). Theoretically, one would expect competition to override facilitation at low plant growth, as availability of the common food source is restricted, whereas facilitation may become increasingly important as plant productivity increases (Cheng and Ritchie 2006). As productivity increases, plant size and the proportion of woody tissue increase, causing plants to be less accessible and palatable to small grazers (Van der Wal et al. 1998, Kuijper et al. 2008). Removal of tall and inedible plant material by large bulk grazers can increase both accessibility and quality of food sources for small herbivores as sprouting tissue is lower in height and richer in nutrients. However, at very high productivity levels, woody plants can outcompete grasses (Sankaran et al. 2005, Hopcraft et al. 2009) and even bulk grazers may not be able to forage, thus reducing the potential for facilitation to occur. Instead facilitation may turn into competition for the remaining scarce grasses under very high productivity levels. Recent experimental evidence with terrestrial invertebrate herbivores shows switches in the direction and strength of positive interactions along plant palatability gradients. Dangles et al. (2013) showed that the interaction between larvae of two potato tuber moths switches from neutral to positive at increasing unpalatability stress, reaching a peak at intermediate levels of plant thickness to further decrease at the highest levels of plant unpalatability (Dangles et al. 2013). Whereas most cases are documented in terrestrial ecosystems, facilitation among herbivores has also been described in marine (Bruno et al. 2003) and freshwater systems (Brönmark et al. 1991, Vanni 2002, Hertonsson et al. 2008, Holomuzki et al. 2010).

We tested experimentally how competition and facilitation between herbivore species change over a manipulated gradient of nutrient availability. We constructed freshwater microcosms with different nutrient levels to assess changes in plant biomass and species composition and the resulting interaction between a generalist and specialist herbivore. Increasing nutrient concentrations can potentially increase macrophyte, filamentous algae, and phytoplankton growth (Brönmark 1985, Underwood et al. 1992, Jones and Sayer 2003), inducing changes in food availability to different types of herbivores. At high nutrient availability, macrophyte biomass decreases due to light limitation by increasing biomass of filamentous algae and phytoplankton (Weisner et al. 1997, Jones and Sayer 2003, Le Bagousse-Pinguet et al. 2012b). We hypothesized that snails, as generalist herbivores, by feeding on filamentous algae, would provide indirect facilitation by making macrophytes more accessible to aquatic caterpillars, which are specialist grazers on macrophytes (Gross and Kornijów 2002). We predicted that caterpillars would be able to have higher growth when snails were present and show the highest positive effects of snails at intermediate levels of nutrient availability and neutral or negative effects at very low or very high nutrient levels.

\section{Methods \\ Study system}

The aquatic caterpillar Acentria ephemerella is a facultative specialist herbivore (sensu Gross and Bakker 2012), which feeds on a limited set of macrophyte species, including Potamogeton perfoliatus L. as one of its favorites (Choi et al. 2002, Le Bagousse-Pinguet et al. 2012a). Caterpillar growth is enhanced by macrophyte quality (high nutrient and low secondary metabolite concentrations [Choi et al. 2002, Miler and Straile 2010]). Within aquatic systems, snails can function as bulk grazers and caterpillars as specialist grazers (sensu terrestrial systems [Huisman and Olff 1998, Arsenault and Owen-Smith 2002]). The pond snail Lymnaea stagnalis is an omnivore that includes macrophytes in its diet (Elger et al. 2007). Snails prefer filamentous algae over macrophytes (Pinowska 2002, Elger et al. 2007), and therefore they can potentially facilitate caterpillars by removing algae and improving access to the macrophytes (Choi et al. 2002, Gross and Kornijów 2002). A facilitative effect of snails on caterpillars may also arise when snails improve food quality for the caterpillars. Through nutrient recycling, snails can increase the nutrient concentration in the water (Pinowska 2002) and perhaps also in the macrophyte tissue. Caterpillars of Acentria ephemerella can be found from May through September in the field, where they complete two to three life cycles per year (Gross et al. 2002). Lymnaea stagnalis snails can be active year round in the field, depending on the water temperatures (Otto and Svensson 1981).

\section{Experimental design}

In order to assess the potential positive effect of snails on the food consumption and growth of caterpillars, we created a gradient of nutrient availability and applied six grazer treatments. We created the nutrient gradient by applying five increasing nutrient levels corresponding to $0.25,0.50,1.00,2.00$, and $4.00 \mathrm{~g}$ slow-release fertilizer in the sediment of each container and we introduced six grazer treatments: a control treatment with no grazers and five treatments with respectively 1 snail, 5 snails, 10 caterpillars, 1 snail +10 caterpillars, and 5 snails +10 caterpillars. The density of 1 snail is similar to intermediate densities used in other studies (Elger et al. 
2007), whereas we added the density of 5 individuals per container in case the duration of the experiment was too short to allow 1 snail to graze down the filamentous algae. Both densities can be found in the field, even though the highest density only occurs in the absence of predation or during drought (Elger et al. 2007). Caterpillar densities in the field have been found to range from $0-165$ individuals per $\mathrm{g}$ dry macrophyte (Gross et al. 2002). The caterpillar density of 10 per container corresponded to 63 individuals per g dry mass of Potamogeton perfoliatus at the time of introduction, corresponding to a moderate grazing pressure (Gross et al. 2002, Miler and Straile 2010). Each nutrient and herbivore treatment combination was randomly assigned to each of 60 experimental units resulting in two replicates per treatment combination.

\section{Experimental setup}

We used 10-L polyethylene containers filled with $1.5 \mathrm{~L}$ sand enriched with a slow-release fertilizer (Osmocote Plus 16N-8P-12K; Scotts Europe BV, Heerlen, The Netherlands) and $8 \mathrm{~L}$ pond water diluted with demineralized water (50:50, conductivity $\sigma=450 \mathrm{~S} / \mathrm{m}$; see Appendix A for abiotic conditions). The nutrient levels were chosen to result in a gradient ranging from low to high sediment nutrient availability for macrophyte growth. The nutrient gradient was based on optimal growing conditions for Potamogeton pectinatus in culture, a species with similar nutrient requirements as Potamogeton perfoliatus (LeBagousse-Pinguet et al. 2012a), which was achieved using 1.2 and $1.3 \mathrm{~g}$ Osmocote, respectively, of the same nutrient composition per liter of sand sediment (Elger et al. 2007, Hidding et al. 2010), corresponding to our treatment of $2 \mathrm{~g}$ Osmocote. We used three lower nutrient levels to mimic decreasing nutrient availability leading to reduced plant biomass and plant quality by means of nutrient concentrations and nutrient ratios. We doubled the optimal nutrient dosage to achieve the highest nutrient level of our gradient at which the macrophyte would just be able to persist, with reduced growth due to a shift to algal dominance. This gradient would most closely mimic the gradient of nutrient availability under which Potamogeton perfoliatus can be found in the field (LeBagousse-Pinguet et al. 2012a). Each container was planted with three clean shoots of approximately $15 \mathrm{~cm}$ plus rhizomes of Potamogeton perfoliatus $(9.7 \pm 1.9 \mathrm{~g}$ wet mass per container [mean $\pm \mathrm{SD}$ ], corresponding to $0.12 \mathrm{~g}$ dry mass of shoot mass) collected from Lakes IJsselmeer $\left(52^{\circ} 50^{\prime} \mathrm{N}, 5^{\circ} 36^{\prime} \mathrm{E}\right)$ and Loenderveen $\left(52^{\circ} 12^{\prime}\right.$ $\mathrm{N}, 5^{\circ} 03^{\prime} \mathrm{E}$ ) in The Netherlands. Filamentous algae and epiphyton developed spontaneously on the planted macrophytes. Plants were allowed to establish and grow during five weeks prior to introduction of the herbivores. In total, 60 containers were placed in a climate room with a $16: 8$ hour day: night regime at $18^{\circ} \mathrm{C}$ and light level of $100 \mu \mathrm{mol} \cdot \mathrm{m}^{-2} \cdot \mathrm{s}^{-1} \mathrm{PAR}$ at the water surface.
Pond snails were collected from the same ponds at Lake Loenderveen, where Potamogeton perfoliatus was collected, and kept in aquaria prior to the introduction of herbivores in the experiment. Caterpillars (eggs and larvae) were collected in Lake Constance $\left(47^{\circ} 39^{\prime} \mathrm{N}\right.$, $9^{\circ} 19^{\prime}$ E), Germany, as caterpillars were not found in sufficient numbers at the time of sampling in Lake Loenderveen. Larvae and eggs were kept in separate containers filled with water from the ponds at Loenderveen and fed with $P$. perfoliatus leaves. Water and leaves were refreshed every two days. All herbivores were introduced at the same day in the experimental containers (snails of $2.7 \pm 0.27 \mathrm{~cm}$ shell length [mean \pm $\mathrm{SD}, n=40$ snails] and caterpillars of the third instar). After three weeks, caterpillars pupated, meaning that caterpillar growth could not be measured anymore. Therefore, we continued the experiment and another 10 caterpillars (newly hatched from the eggs that we had collected) were introduced per container with a caterpillar treatment at the start of the fourth week of the experiment. The experiment was terminated two weeks later before these caterpillars pupated, having run in total five weeks after the first introduction of the herbivores. Caterpillar growth was measured on this second set of caterpillars.

\section{Measurements}

Water conditions.-We measured conductivity, $\mathrm{pH}$, and the phytoplankton and nutrient concentration in the water column at the end of the experiment. Conductivity and $\mathrm{pH}$ were measured in situ with a portable probe (340i SET, 2E30-101B02; WTW GmbH, Weilheim, Germany). To determine phytoplankton concentration and water nutrient concentration a $50-\mathrm{mL}$ water sample was taken from each container. The phytoplankton concentration of the water was measured as the concentration of chlorophyll $a$ on a PhytoPAM phytoplankton analyzer (Heinz Walz GmbH, Effeltrich, Germany). Subsequently the water was filtered over a $0.7-\mu \mathrm{m}$ mesh filter (Whatman GF/F) and the filtrate was analyzed with continuous flow analysis on an autoanalyzer (QuAAtro; Seal Analytical, B. de Ronde, Abcoude, The Netherlands) to determine $\mathrm{PO}_{4}, \mathrm{NO}_{3}$, and $\mathrm{NH}_{4}$ concentrations. The results can be found in Appendix A.

Macrophytes and algae.-Aboveground biomass of macrophytes and biomass of filamentous algae was harvested by hand at the end of the experiment, washed and dried in the oven at $60^{\circ} \mathrm{C}$ for $48 \mathrm{~h}$, and weighed. Epiphyton biomass was estimated as $\mathrm{mg} / \mathrm{g}$ of macrophyte dry mass by shaking three harvested Potamogeton leaves for one minute in a bottle with $50 \mathrm{~mL}$ filtered water free of algae, following Zimba and Hopson (1997). The water was subsequently filtered using 0.7$\mu \mathrm{m}$ mesh filters (Whatman GF/F) and algal dry mass on the filters was determined after drying in the oven at $60^{\circ} \mathrm{C}$ for $48 \mathrm{~h}$. Potamogeton leaves were added to the rest of the harvested Potamogeton for further analysis. We 
found that epiphyton biomass was generally less than $5 \%$ of the biomass of the filamentous algae (data not shown), which were very abundant. Therefore, we further focused on the role of filamentous algae.

We determined plant nutrient ratios (C:N and $\mathrm{C}: \mathrm{P})$ in the ground macrophyte biomass. Plant $\mathrm{C}$ and $\mathrm{N}$ concentrations were determined with a FLASH 2000 Organic Elemental Analyzer (Interscience, Breda, The Netherlands). Plant P concentration was measured by incinerating grounded homogenized dry material for 30 minutes at $500^{\circ} \mathrm{C}$, followed by digestion in $2.5 \% \mathrm{~K}_{2} \mathrm{~S}_{2} \mathrm{O}_{8}$ (Murphy and Riley 1962), before analysis with a QuAAtro CFA flow analyzer (Seal Analytical, Beun de Ronde, Abcoude, The Netherlands).

Herbivores.-Caterpillar mass was determined at the end of the experiment as dry mass $(\mu \mathrm{g})$ per individual after drying the caterpillars in the oven at $60^{\circ} \mathrm{C}$ for $24 \mathrm{~h}$. The shell length ( $\mathrm{mm}$, maximum length taken from aperture to tip) of snails was determined at the start and end of the experiment. Shell length of Lymnaea stagnalis is a proxy for dry mass of the soft snail tissue (Elger and Barrat-Segretain 2002). Snail growth rate was calculated as $g=\left(\ln \left[x_{1}\right]-\ln \left[x_{0}\right]\right) / d$ where $x_{0}$ and $x_{1}$ represent snail length at the start and end of the experiment and $d$ is the experimental duration in days.

\section{Statistical analysis}

Relative effect sizes of snail or caterpillar presence on each other were calculated as the log response ratio. For example the effect of the presence of one snail on caterpillar biomass is expressed as caterpillar $\log$ response ratio $=\ln ($ [caterpillar biomass in 1 snail +10 caterpillars treatment]/[caterpillar biomass in 10 caterpillars, no snail treatment]) (Hedges et al. 1999). Mean $\log$ response ratios of caterpillars $( \pm 95 \%$ confidence intervals) in response to nutrient availability were analyzed with a linear least squares regression model. Effects of treatments on biomass of macrophytes, filamentous algae, and phytoplankton, $\mathrm{C}: \mathrm{N}$ and $\mathrm{C}: \mathrm{P}$ ratio in macrophytes, as well as on abiotic variables, were analyzed using linear least squares regression models. To allow for nonlinear responses to nutrient additions, we included nutrients $(N)$ also as a quadratic term $\left(N^{2}\right)$ in the models. We examined full models including higher-order interactions and removed nonsignificant $(P>0.05)$ interactions and variables subsequently. However, a nonsignificant main effect was not removed when interactions involving this specific main effect were significant (marginality principle [Venables and Ripley 2002]). Likewise, when there was no nonlinear effect of nutrients, $N$, but not $N^{2}$ was retained in the models. Residuals of final models were checked for normality and variance homogeneity. When diagnostic plots indicated deviations from normality and variance homogeneity, data were log-transformed. As Potamogeton C:N and C:P ratios were strongly hyperbolically related to nutrient concentrations, nutrient concentrations were $1 / x$ transformed prior to analysis of
Potamogeton C:N and C:P ratios. All analyses were performed using R version 2.13.0 (R Development Core Team 2011).

\section{RESUlTS}

\section{Plant biomass and macrophyte nutrient ratios along the nutrient gradient}

In the absence of herbivores, macrophyte biomass showed an optimum at intermediate nutrient levels (Fig. 1a; linear model with quadratic term, $R^{2}=0.88, P=$ $0.001)$. Biomass of filamentous algae increased linearly along the nutrient gradient (Fig. 1b; linear model, $R^{2}=$ $0.69, P=0.007)$. Phytoplankton concentration increased exponentially with nutrient availability (Fig. 1c; linear model with log-transformed chlorophyll $a$ data, $R^{2}=$ 0.86, $P<0.001)$. The total biomass of the primary producers (macrophytes, filamentous algae, and phytoplankton combined) increased with nutrient availability in a satiating way $\left(R^{2}=0.68, P=0.030\right)$. Increased nutrient availability reduced the $C: N$ and $C: P$ ratio in macrophytes (Appendix B: Fig. B1, linear models with $1 / x$-transformed nutrient data, $R^{2}=0.81, P<0.001$ and $R^{2}=0.68, P<0.01$, respectively).

\section{Herbivore facilitation along the nutrient gradient}

The effect of snails on caterpillar biomass, i.e., caterpillar log response ratios, showed an optimum at intermediate nutrient levels (Fig. 2; quadratic regression, $\left.R^{2}=0.63, P<0.001\right)$. Snails had the strongest positive effect on caterpillar log response ratios at intermediate nutrient concentrations, whereas their effect became negative or neutral toward very low or very high nutrient levels. The effect of snail density was not significant ( $t=0.57, \mathrm{df}=14, P=0.58)$, i.e., the effect of snails on caterpillar log response ratio did not differ significantly between the one-snail and five-snails treatments. The $95 \%$ confidence intervals of the predicted mean caterpillar log response ratio did just not include zero at the lowest nutrient concentration and were clearly higher than zero at medium nutrient concentration indicating neutral to negative interactions at the lowest nutrient concentration and facilitation at medium nutrient concentrations (Fig. 2). In contrast, at high nutrient concentrations, confidence intervals included zero indicating no effect of snails on caterpillars. Caterpillars did not affect snail growth rates, i.e., snail log response ratios did not differ significantly from zero (Appendix C: Fig. C1, one-sample $t$ test, $t=-0.99$, df $=$ $19, P=0.38)$.

\section{Mechanisms of facilitation}

Snails did not affect macrophyte biomass (Fig. 3a; see Appendix D: Table D1, for results of the statistical analyses). Caterpillars, on the other hand, reduced macrophyte biomass (Fig. 3a), but this effect depended on the nutrient availability (interaction caterpillar presence $\times$ nutrient $^{2}$, Table D1). Caterpillars reduced macrophyte biomass most at intermediate nutrient 

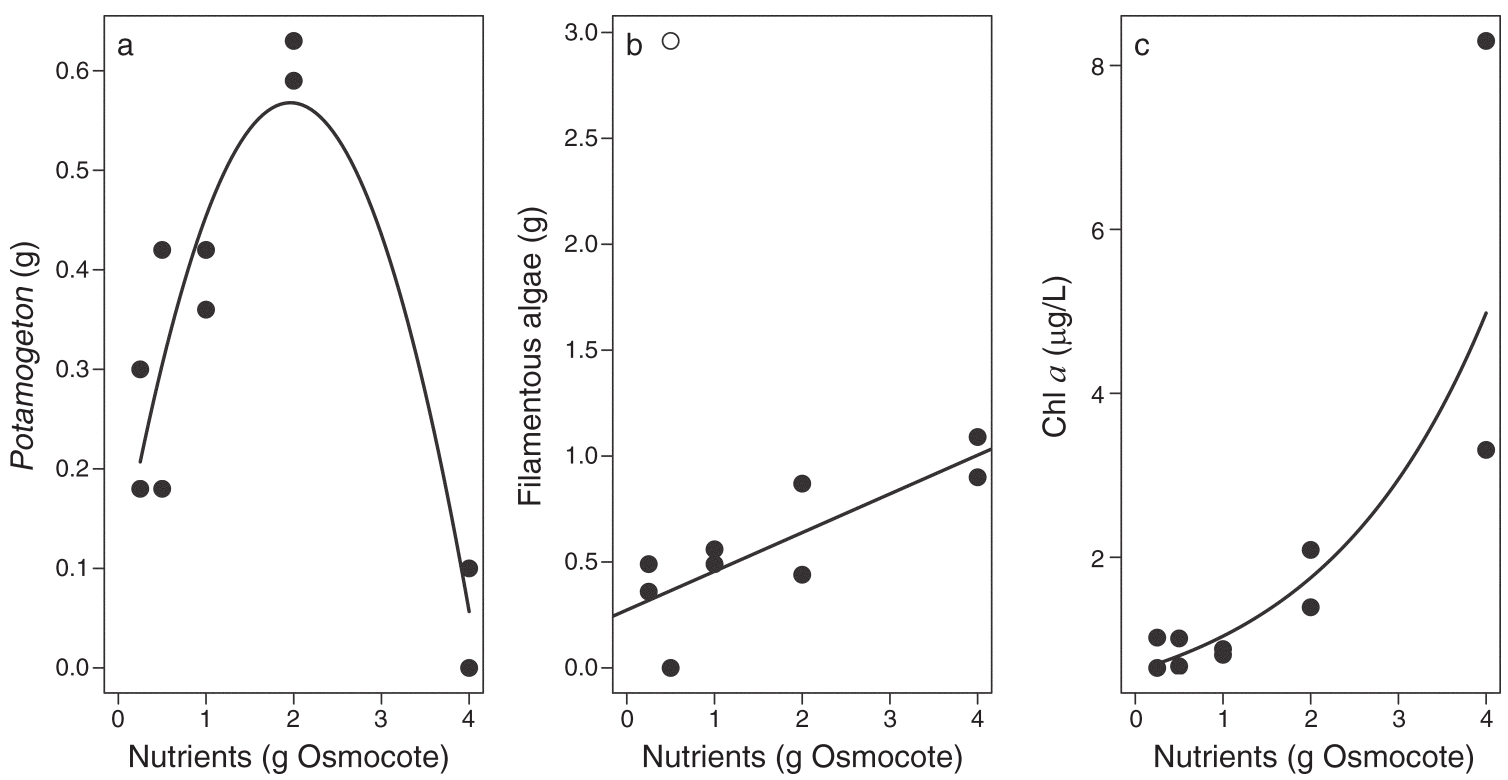

FIG. 1. Biomass of (a) macrophytes (Potamogeton), (b) filamentous algae, and (c) phytoplankton over the nutrient gradient in the absence of herbivores, at the end of the experiment (dry mass). Solid lines indicate significant regressions between nutrient availability and plant growth. For filamentous algae one outlier (indicated by an open circle) was excluded from statistical analysis (Bonferroni-adjusted outlier test; studentized residual $=11.75, \mathrm{df}=7, P<0.001$ ). Biomass is expressed as g dry mass per pot for macrophytes and filamentous algae and as $\mu \mathrm{g}$ chlorophyll $a$ per liter of water for phytoplankton.

availability (Appendix E: Fig. E1). Snails significantly reduced the biomass of filamentous algae, which was almost absent at the highest snail density, whereas the biomass of filamentous algae significantly increased in the presence of caterpillars (Fig. 3b; Table D1). The positive effect of caterpillars on filamentous algae decreased with both increasing nutrients and increasing snail density (significant interactions, Table D1). Snails did not affect the C:N and C:P ratios in macrophytes, whereas caterpillar presence increased the $\mathrm{C}: \mathrm{N}$ and $\mathrm{C}: \mathrm{P}$ ratios in the macrophytes (Fig. 3c; Table D1).

\section{DisCUSSION}

\section{Facilitation along a gradient of nutrient availability}

We found that the positive interaction between these aquatic herbivores peaked at intermediate nutrient availability. Previous work in terrestrial systems had suggested that contrasting productivity levels in response to resource availability could shift the interaction between herbivores from competition at low productivity levels to facilitation at high productivity levels (Cheng and Ritchie 2006, Odadi et al. 2011). Also switches from neutral to positive interactions have been observed along plant palatability gradients (Dangles et al. 2013). Our study provides experimental proof that correlational field observations fit in a pattern of systematic change of facilitation between herbivores over environmental gradients of resource availability. We found evidence that facilitation among aquatic herbivores follows a hump-shaped curve over the experimental gradient of nutrient availability. These

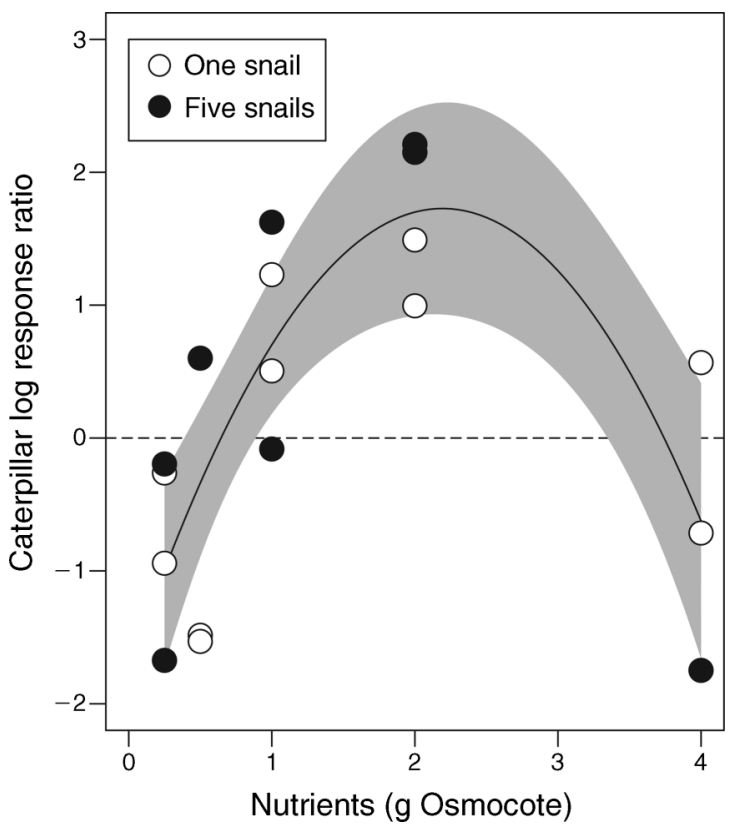

FIG. 2. The effect of snail presence on caterpillar biomass, expressed as caterpillar log response ratios, over the nutrient gradient. There was a significant hump-shaped relationship between caterpillar log response ratio and nutrient availability (solid line; see Results for statistical analysis). The effect of snail density was not significant. The shaded area indicates the $95 \%$ confidence interval; the dotted line indicates zero effect of snails on caterpillar log response ratio. 

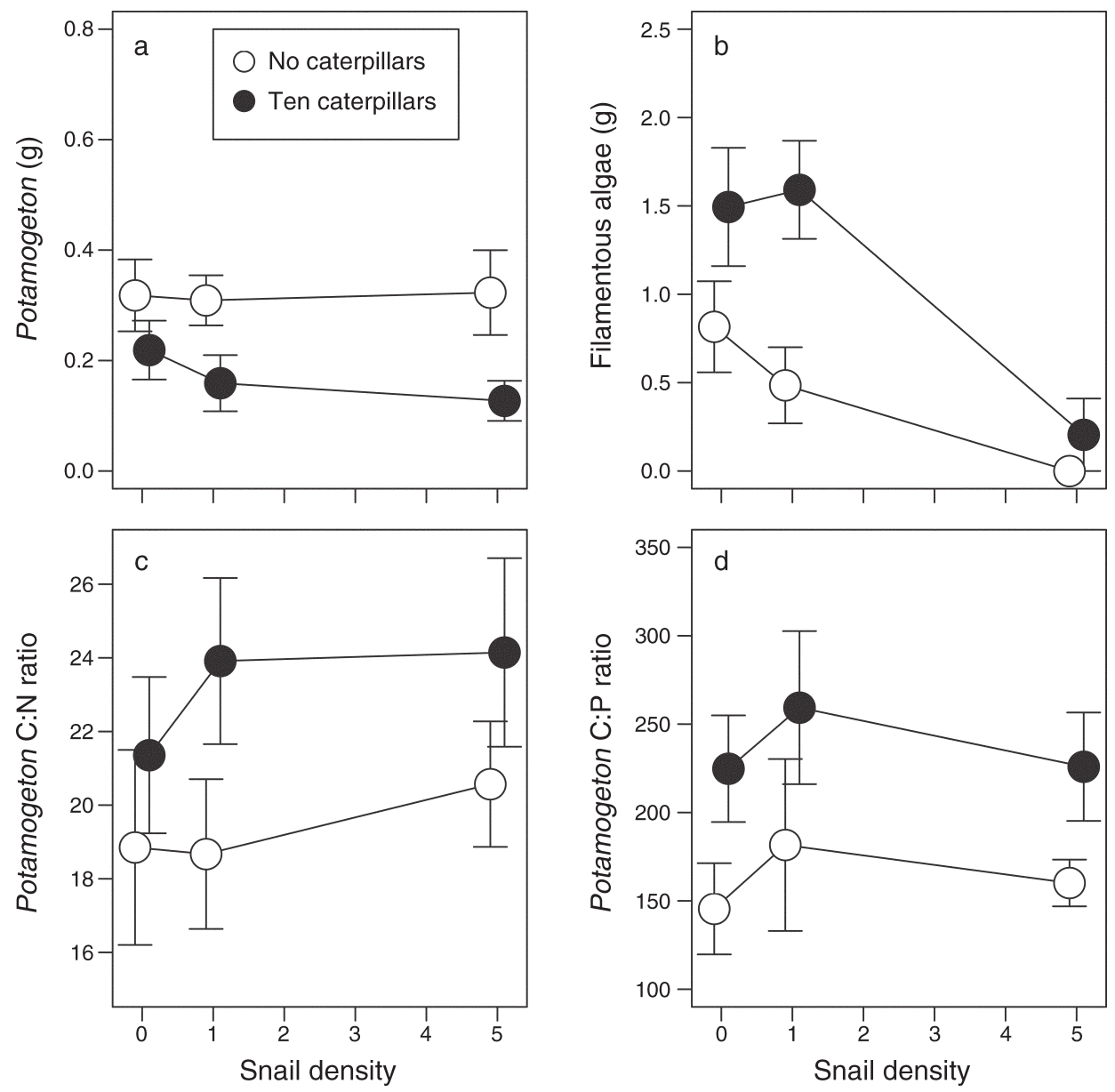

FIG. 3. Impact of snails and caterpillars on (a) macrophyte biomass (g dry mass), (b) the biomass of filamentous algae, (c) macrophyte C:N molar ratio, and (d) macrophyte C:P molar ratio. Values are means \pm SE. Results of statistical macrophyte analyses are given in Appendix D.

results support theoretical models that predict the role of facilitation to peak at intermediate levels of environmental stress (Maestre et al. 2009, Holmgren and Scheffer 2010, Smit et al. 2010).

\section{Facilitation in the freshwater model system}

Higher nutrient levels increased overall total plant biomass but induced a shift toward dominance of filamentous algae at the expense of macrophytes. At high nutrient availability, filamentous algae and phytoplankton may have outcompeted the macrophytes by inducing light limitation, which can lead to a strong decline in macrophyte biomass as is commonly observed in mesocosm experiments and field studies (Weisner et al. 1997, Jones and Sayer 2003, Le Bagousse-Pinguet et al. 2012b). Our model system therefore represented macrophyte growth along a nutrient gradient mimicking a range from oligotrophic to eutrophic conditions, as can be found in the field. At high nutrient availability, macrophyte biomass was so low that an effect of snail facilitation, if present, was not detectable. At low nutrient availability, caterpillar growth tended to be unaffected or slightly reduced in the presence of snails. This could indicate that the biomass of filamentous algae was so low that caterpillars still had access to the macrophytes without the need for snails to remove filamentous algae. In addition, the $\mathrm{C}$ :nutrient ratios in the macrophyte, which were highest at the lowest nutrient level, may have posed a constraint on caterpillar growth (Miler and Straile 2010). Negative effects on caterpillar growth could potentially have arisen from competition between caterpillars and snails for the sparse macrophytes; however, we found no evidence that snails actually reduced macrophyte biomass at low nutrient availability. The potential negative effect of snails on caterpillar growth at the lowest nutrient level seemed only marginally significant; if present, the effect was small and it remains unclear what caused it. At intermediate nutrient levels, snails could clean the macrophytes from fast-growing filamentous algae (Brönmark 1985, Underwood et al. 1992, Jones et al. 2002) improving access for caterpillars, while increased feeding of snails on the algae left the macrophytes as food 
source for the caterpillars, profiting optimally from the snails presence. At the highest nutrient level, snails still removed the filamentous algae, but this did not result in increased macrophyte biomass; due to increased phytoplankton densities macrophyte growth could still be light limited (Le Bagousse-Pinguet et al. 2012b). As a result caterpillar growth may have suffered from reduced macrophyte biomass. Snails could also facilitate caterpillars by increasing macrophyte biomass or macrophyte nutrient concentration through nutrient recycling and cleaning of macrophytes (Pinowska 2002, Lombardo and Cooke 2004). As we did not find any evidence that snails increased macrophyte biomass or macrophyte nutrient concentration or nutrient ratios, we suggest that improving food accessibility is the most likely mechanism that explains the observed facilitative effect of snails on caterpillars (Gross and Kornijów 2002).

In our experiment, caterpillar presence did not affect snail growth. However, caterpillars did affect the quantity, accessibility, and quality of their own food source. Caterpillar grazing reduced the biomass of the macrophytes, which is commonly found (Gross et al. 2001, Miler and Straile 2010, Le Bagousse-Pinguet et al. $2012 a$ ) and a logical consequence of grazing. Interestingly, caterpillar presence resulted in enhanced growth of filamentous algae, which would limit the accessibility of the macrophytes for themselves. This may be the result of the regeneration and release of nutrients associated with caterpillar feeding on macrophytes, which could promote the growth of filamentous algae, as has been observed for other aquatic herbivores (Brönmark et al. 1991, Pinowska 2002, Vanni 2002). Furthermore, caterpillar presence reduced the quality of the macrophytes as food plant, which was reflected in enhanced macrophyte $\mathrm{C}: \mathrm{N}$ and $\mathrm{C}: \mathrm{P}$ ratios in the caterpillar treatments. An increased $\mathrm{C}$ : nutrient ratio or decreased concentration of $\mathrm{N}$ or $\mathrm{P}$ of plants generally indicates low food quality for aquatic herbivores (Elser et al. 2000, Fink and Von Elert 2006, Miler and Straile 2010, Dorenbosch and Bakker 2011). The increased macrophyte $\mathrm{C}: \mathrm{P}$ and $\mathrm{C}: \mathrm{N}$ ratios in the caterpillar treatment might indicate nutrient reallocation in the plant and hence controlled leaf senescence as a response to caterpillar grazing as has been previously found (Miler and Straile 2010).

The enhanced growth of filamentous algae in the presence of caterpillars underlines the potential importance of snails as benefactors of caterpillars. Potentially caterpillars might also act as a benefactor of snails, through their enhancement of filamentous algae biomass, as the snails consume filamentous algae. However, we found no evidence of a facilitative effect of caterpillars on snails in our experiment.

\section{Facilitation in aquatic and terrestrial herbivore communities}

Facilitation among herbivores has been mostly documented in terrestrial ecosystems. In grasslands, facilitation is thought to be strongest under productive conditions (Huisman and Olff 1998, Van der Wal et al. 2000, Cheng and Ritchie 2006). With increasing productivity, plants become taller and accumulate stems and woody material, which decreases food quality and accessibility to smaller grazers (Van der Wal et al. 1998). This is true within plant species, but also plant communities shift toward dominance by taller and woodier species with increasing productivity (Kuijper et al. 2008). Bulk grazers that can remove tall and indigestible vegetation, can retard this process, and facilitate small specialist grazers, but fail to prevent it in the longer term (Olff et al. 1999, Van der Wal et al. 2000). Therefore, at very high productivity, the interaction between bulk and specialist grazers might turn into competition for scarce food, namely the grasses in between the dominant woody plants. Indeed increasing plant unpalatability experimentally can switch the interaction between herbivores from neutral to positive until a certain point to further decrease at the highest levels of plant unpalatability (Dangles et al. 2013).

In our aquatic system, we did find facilitation to increase with nutrient level, as hypothesized for terrestrial systems. By extending the gradient to higher nutrient levels we found a shift from a linear to a hump-shaped relationship between nutrient level and facilitation. In our aquatic system, no woody species exist, but with increasing nutrient availability, the biomass of the primary producers increased and shifted toward a functional group that causes light limitation (as trees or shrubs would do in a terrestrial system) and cannot be consumed by our grazers, e.g., the phytoplankton. Comparable to the transition from herbaceous to woody plants with increasing resource availability observed in terrestrial systems (Van der Wal et al. 2000, Sankaran et al. 2005, Hopcraft et al. 2009), we also found a hierarchy of responses of primary producers to nutrient availability. Macrophytes initially have the largest increase but decline at the highest nutrient availability, filamentous algae increase linearly, and phytoplankton exponentially with nutrient availability.

\section{Conclusions}

Our results demonstrate that facilitation between herbivores follows a hump-shaped relationship along a gradient of nutrient availability and suggests that there are remarkable similarities in how interspecific interactions change along environmental gradients among aquatic and terrestrial habitats. Understanding how interspecific interactions may change in strength and direction along environmental gradients is important to predict how the diversity and structure of communities may respond to the introduction or removal of herbivore species in ecosystems.

\section{ACKNOWLEDGMENTS}

Nils Schölzel transported the caterpillars; Nico Helmsing conducted the chemical analysis for nutrient concentrations in water and plant samples. We thank two anonymous reviewers 
for insightful comments. E. S. Bakker was funded by a VENI grant (863.07.006) from the Netherlands Organisation of Scientific Research (NWO). This is publication 5418 of the NIOO-KNAW Netherlands Institute of Ecology.

\section{Literature Cited}

Arsenault, R., and N. Owen-Smith. 2002. Facilitation versus competition in grazing herbivore assemblages. Oikos 97:313318.

Bakker, E. S., H. Olff, and J. M. Gleichman. 2009. Contrasting effects of large herbivore grazing on smaller herbivores. Basic and Applied Ecology 10:141-150.

Bertness, M. D., and R. Callaway. 1994. Positive interactions in communities. Trends in Ecology and Evolution 9:191-193.

Brönmark, C. 1985. Interactions between macrophytes, epiphytes and herbivores: an experimental approach. Oikos 45: 26-30.

Brönmark, C., S. D. Rundle, and A. Erlandsson. 1991. Interactions between freshwater snails and tadpoles: competition and facilitation. Oecologia 87:8-18.

Brooker, R. W., D. Scott, S. C. F. Palmer, and E. Swaine. 2006. Transient facilitative effects of heather on Scots pine along a grazing disturbance gradient in Scottish moorland. Journal of Ecology 94:637-645.

Bruno, J. F., J. J. Stachowicz, and M. D. Bertness. 2003. Inclusion of facilitation into ecological theory. Trends in Ecology and Evolution 18:119-125.

Bulleri, F., C. Cristaudo, T. Alestra, and L. Benedetti-Cecchi. 2011. Crossing gradients of consumer pressure and physical stress on shallow rocky reefs: a test of the stress-gradient hypothesis. Journal of Ecology 99:335-344.

Callaway, R. M., et al. 2002. Positive interactions among alpine plants increase with stress. Nature 417:844-848.

Cardinale, B. J., M. A. Palmer, and S. L. Collins. 2002. Species diversity enhances ecosystem functioning through interspecific facilitation. Nature 415:426-429.

Cavieres, L., E. I. Badano, A. Sierra-Almeida, S. GómezGonzález, and M. A. Molina-Montenegro. 2006. Positive interactions between alpine plant species and the nurse cushion Laretia acaulis do not increase with elevation in the Andes of central Chile. New Phytologist 169:59-69.

Cheng, E., and M. E. Ritchie. 2006. Impacts of simulated livestock grazing on Utah prairiedogs (Cynomys parvidens) in a low productivity ecosystem. Oecologia 147:546-555.

Choi, C., C. Bareiss, O. Walenciak, and E. M. Gross. 2002. Impact of polyphenols on growth of the aquatic herbivore Acentria ephemerella. Journal of Chemical Ecology 28:22452256.

Dangles, O., M. Herrera, and F. Anthelme. 2013. Experimental support of the stress-gradient hypothesis in herbivoreherbivore interactions. New Phytologist 197:405-408.

Dorenbosch, M., and E. S. Bakker. 2011. Herbivory in omnivorous fishes: effect of plant secondary metabolites and prey stoichiometry. Freshwater Biology 56:1783-1797.

Duffy, J. E., J. P. Richardson, and E. A. Canuel. 2003. Grazer diversity effects on ecosystem functioning in seagrass beds. Ecology Letters 6:637-645.

Elger, A., and M. H. Barrat-Segretain. 2002. Use of the pond snail Lymnaea stagnalis (L.) in laboratory experiments for evaluating macrophyte palatability. Archiv für Hydrobiologie 153:669-683.

Elger, A., T. T. De Boer, and M. E. Hanley. 2007. Invertebrate herbivory during the regeneration phase: experiments with a freshwater angiosperm. Journal of Ecology 95:106-114.

Elser, J. J., et al. 2000. Nutritional constraints in terrestrial and freshwater foodwebs. Nature 408:578-580.

Fink, P., and E. Von Elert. 2006. Physiological responses to stoichiometric constraints: nutrient limitation and compensatory feeding in a freshwater snail. Oikos 115:484-494.

Gross, E. M., and E. S. Bakker. 2012. The role of plant secondary metabolites in freshwater macrophyte-herbivore interactions: limited or unexplored chemical defences. Pages 154-169 in G. R. Iason, M. Dicke, and S. E. Hartley, editors. The ecology of plant secondary metabolites from genes to global processes. Cambridge University Press, Cambridge, UK.

Gross, E. M., C. Feldbaum, and C. Choi. 2002. High abundance of herbivorous Lepidoptera larvae (Acentria ephemerella Denis \& Schiffermuller) on submersed macrophytes in Lake Constance (Germany). Archiv für Hydrobiologie 155:1-21.

Gross, E. M., R. L. Johnson, and N. G. Hairston. 2001. Experimental evidence for changes in submersed macrophyte species composition caused by the herbivore Acentria ephemerella (Lepidoptera). Oecologia 127:105-114.

Gross, E. M., and R. Kornijów. 2002. Investigation on competitors and predators of herbivorous aquatic Lepidoptera (Acentria ephemerella) on submersed macrophytes in a large prealpine lake. Verhandlungen der Internationalen Vereinigung für Limnologie 28:721-725.

Hacker, S. D., and S. D. Gaines. 1997. Some implications of direct positive interactions for community species diversity. Ecology 78:1990-2003.

Hedges, L. V., J. Gurevitch, and P. S. Curtis. 1999. The metaanalysis of response ratios in experimental ecology. Ecology 80:1150-1156.

Hertonsson, P., K. Åbjörnsson, and C. Brönmark. 2008. Competition and facilitation within and between a snail and a mayfly larva and the effect on the grazing process. Aquatic Ecology 42:669-677.

Hidding, B., R. J. Brederveld, and B. A. Nolet. 2010. How a bottom-dweller beats the canopy: inhibition of an aquatic weed (Potamogeton pectinatus) by macroalgae (Chara spp.). Freshwater Biology 55:1758-1768.

Holmgren, M., L. Gómez-Aparicio, J. L. Quero, and F. Valladares. 2012. Non-linear effects of drought under shade: reconciling physiological and ecological models in plant communities. Oecologia 169:293-305.

Holmgren, M., and M. Scheffer. 2010. Strong facilitation in mild environments: the stress gradient hypothesis revisited. Journal of Ecology 98:1269-1275.

Holomuzki, J. R., J. W. Feminella, and M. E. Power. 2010. Biotic interactions in freshwater benthic habitats. Journal of the North American Benthological Society 29:220-244.

Hopcraft, J. G. C., H. H. Olff, and A. R. E. Sinclair. 2009. Herbivores, resources and risks: alternating regulation along primary environmental gradients in savannas. Trends in Ecology and Evolution 25:119-128.

Huisman, J., and H. Olff. 1998. Competition and facilitation in multispecies plant-herbivore systems of productive environments. Ecology Letters 1:25-29.

Jones, J. I., and C. D. Sayer. 2003. Does the fish-invertebrateperiphyton cascade precipitate plant loss in shallow lakes? Ecology 84:2155-2167.

Jones, J. I., J. O. Young, J. W. Eaton, and B. Moss. 2002. The influence of nutrient loading, dissolved inorganic carbon and higher trophic levels on the interaction between submerged plants and periphyton. Journal of Ecology 90:12-24.

Kawai, T., and M. Tokeshi. 2007. Testing the facilitationcompetition paradigm under the stress-gradient hypothesis: decoupling multiple stress factors. Proceedings of the Royal Society B 274:2503-2508.

Krueger, K. 1986. Feeding relationships among bison, pronghorn, and prairie dogs: an experimental analysis. Ecology 67: $760-770$.

Kuijper, D. P. J., P. Beek, S. E. Van Wieren, and J. P. Bakker. 2008. Time-scale effects in the interaction between a large and a small herbivore. Basic and Applied Ecology 9:126-134.

Le Bagousse-Pinguet, Y., E. M. Gross, and D. Straile. $2012 a$. Release from competition and protection determine the outcome of plant interactions along a grazing gradient. Oikos 121:95-101. 
Le Bagousse-Pinguet, Y., P. Liancourt, N. Gross, and D Straile. 2012b. Indirect facilitation promotes macrophyte survival and growth in freshwater ecosystems threatened by eutrophication. Journal of Ecology 100:530-538.

Lombardo, P., and G. D. Cooke. 2004. Resource use and partitioning by two co-occurring freshwater gastropod species. Archiv für Hydrobiologie 159:229-251.

Maestre, F. T., M. A. Bowker, C. Escolar, M. D. Puche, S. Soliveres, S. Maltez-Mouro, P. Garcia-Palacios, A. P. Castillo-Monroy, I. Martinez, and A. Escudero. 2010. Do biotic interactions modulate ecosystem functioning along stress gradients? Insights from semi-arid plant and biological soil crust communities. Philosophical Transactions of the Royal Society B 365:2057-2070.

Maestre, F. T., R. M. Callaway, F. Valladares, and C. J. Lortie. 2009. Refining the stress-gradient hypothesis for competition and facilitation in plant communities. Journal of Ecology 97: 199-205.

Maestre, F. T., and J. Cortina. 2004. Do positive interactions increase with abiotic stress? A test from a semi-arid steppe. Proceedings of the Royal Society B 271:S331-S333.

Maestre, F. T., F. Valladares, and J. F. Reynolds. 2005. Is the change of plant-plant interactions with abiotic stress predictable? A meta-analysis of field results in arid environments. Journal of Ecology 93:748-757.

Michalet, R., R. W. Brooker, L. A. Cavieres, Z. Kikvidze, C. J. Lortie, F. I. Pugnaire, A. Valiente-Baunet, and R. M. Callaway. 2006. Do biotic interactions shape both sides of the humped-back model of species richness in plant communities? Ecology Letters 9:767-773.

Miler, O., and D. Straile. 2010. How to cope with a superior enemy? Plant defence strategies in response to annual herbivore outbreaks. Journal of Ecology 98:900-907.

Murphy, J., and J. P. Riley. 1962. A modified single solution method for determination of phosphate in natural waters. Analytica Chimica Acta 27:31-36.

Odadi, W. O., M. K. Karachi, S. A. Abdulrazak, and T. P. Young. 2011. African wild ungulates compete with or facilitate cattle depending on season. Science 333:1753-1755.

Olff, H., F. W. M. Vera, J. Bokdam, E. S. Bakker, J. M. Gleichman, K. De Maeyer, and R. Smit. 1999. Shifting mosaics in grazed woodlands driven by the alternation of plant facilitation and competition. Plant Biology 1:127-137.
Otto, C., and B. S. Svensson. 1981. How do macrophytes growing in or close to water reduce their consumption by aquatic herbivores? Hydrobiologia 78:107-112.

Pinowska, A. 2002. Effects of snail grazing and nutrient release on growth of the macrophytes Ceratophyllum demersum and Elodea canadensis and the filamentous green alga Cladophora sp. Hydrobiologia 479:83-94.

R Development Core Team. 2011. R: a language and environment for statistical computing. R Foundation for Statistical Computing, Vienna, Austria. http://www. R-project.org

Sankaran, M., et al. 2005. Determinants of woody cover in African savannas. Nature 438:846-849.

Smit, C., M. Rietkerk, and M. J. Wassen. 2010. Inclusion of biotic stress (consumer pressure) alters predictions from the stress gradient hypothesis. Journal of Ecology 97:1215-1219.

Smit, C., C. Vandenberghe, J. Den Ouden, and H. MüllerSchärer. 2007. Nurse plants, tree saplings and grazing pressure: changes in facilitation along a biotic environmental gradient. Oecologia 152:265-273.

Underwood, G. J. C., J. D. Thomas, and J. H. Baker. 1992. An experimental investigation of interactions in snail-macrophyte-epiphyte systems. Oecologia 91:582-595.

Van der Wal, R., J. Van de Koppel, and M. Sagel. 1998. On the relation between herbivore foraging efficiency and plant standing crop: an experiment with barnacle geese. Oikos 82: 123-132.

Van der Wal, R., H. Van Wijnen, S. Van Wieren, O. Beucher, and D. Bos. 2000. On facilitation between herbivores: how brent geese profit from brown hares. Ecology 81:969-980.

Vanni, M. J. 2002. Nutrient cycling by animals in freshwater ecosystems. Annual Review of Ecology and Systematics 33: 341-370.

Venables, W. N., and B. D. Ripley. 2002. Modern applied statistics with S. Springer, New York, New York, USA.

Weisner, S. E. B., J. A. Strand, and H. Sandsten. 1997. Mechanisms regulating abundance of submerged vegetation in shallow eutrophic lakes. Oecologia 109:592-599.

Zimba, P. V., and M. S. Hopson. 1997. Quantification of epiphyte removal efficiency from submersed aquatic plants. Aquatic Botany 58:173-179.

\section{Supplemental Material}

\section{Appendix A}

A figure and table with statistical results for the effect of nutrient availability and herbivore presence on water conditions measured at the end of the experiment (Ecological Archives E094-161-A1).

\section{Appendix B}

A figure showing nutrient ratios in the macrophyte in the absence of herbivores (Ecological Archives E094-161-A2).

\section{Appendix C}

A figure showing the effect of caterpillar presence on snail growth along the gradient of nutrient availability (Ecological Archives E094-161-A3)

\section{Appendix D}

A table with the analysis of the effect of herbivore treatments and nutrient availability on biomass of macrophytes and filamentous algae and the C:N and C:P ratio of macrophytes (Ecological Archives E094-161-A4).

\section{Appendix E}

A figure illustrating the interactive effect of caterpillar presence and nutrient availability on macrophyte biomass (Ecological Archives E094-161-A5). 